\title{
Factors predicting mood changes in oral contraceptive pill users
}

\author{
Ghodratollah Shakerinejad', Alireza Hidarnia ${ }^{1 *}$, Mohammad Esmaeil Motlagh², Khodabakhsh Karami², \\ Shamsoddin Niknami ${ }^{1}$ and Ali Montazeri ${ }^{4^{*}}$
}

\begin{abstract}
Background: Over 100 million women worldwide are using oral contraceptives pills (OCP) and mood changes were being as the primary reason for OCP discontinuation. The purpose of this study was to determine the prevalence and predicting factors of mood changes in oral contraceptive pills users.

Methods: This was a cross-sectional study of 500 women aged 15-49 years old using low dose (LD) pills attending family planning centers in Ahwaz, Iran. Data were collected via face-to-face interviews using a structured questionnaire including items on demographic, self-efficacy and mood change. Both univarate and multiple logistic regression analyses were performed to assess the relationship between reported mood change and the independent variables.

Results: In all 406 women reported that they did experience OCP side effects. Of these, 37.7\% of women ( $n=153$ ) reported mood changes due to OCP use. The results of multiple logistic regression revealed that place of living $(O R=2.57,95 \% C l=1.06-6.20, p=0.03)$, not receiving information on $O C P$ side effects $(O R=1.80,95 \%$ $C l=1.15-2.80, p=0.009)$, and lower self-efficacy $(O R=0.87,95 \% \mathrm{Cl}=0.80-0.94, p=0.001)$ were significant predictors of mood changes.

Conclusion: The findings from this study indicated that the prevalence of reported mood changes due to OCP use among Iranian women appeared to be consistent with other studies. In addition the findings showed that receiving information on OCP side effects from health care workers and self-efficacy were important predicting factors for mood changes. Indeed implementing educational programs and improving self-efficacy among women are recommended.
\end{abstract}

\section{Background}

In order to promote women's health universal access to reproductive health including using the correct methods of contraception is one of the Millennium Development Goals (MDGs) [1]. Oral contraceptive pills are one of the most common methods of contraception and over 100 million women are using oral contraceptives pills $(\mathrm{OCP})$ worldwide [2]. Also there is evidence that more than $84 \%$ of women during their life use one of the hormonal methods in order to prevent pregnancy [3]. However, due to side effects almost $50 \%$ of new OCP users discontinue using the pills

\footnotetext{
*Correspondence: Hidarnia@modares.ac.ir; montazeri@acecr.ac.ir 'Department of Health Education, Faculty of Medical Sciences, Tarbiat Modares University, Tehran, Iran

${ }^{4}$ Mental Health Research Group, Health Metrics Research Centre, Iranian Institute for Health sciences Research, ACECR, Tehran, Iran

Full list of author information is available at the end of the article
}

almost six to twelve months after the start. As such 'mood changes' and depression considered as being the primary reason for OCP discontinuation $[4,5]$.

Since the introduction of OCP in 1960, many studies have examined the extent to which oral contraceptive pills affected mood and depression. Nevertheless, the results of the research have been inconsistent and there has been litthe progress in identifying predictors or causes of OCPrelated mood changes [6-8]. 'Mood changes' refer to one's general emotional climate, and emotional state at a particular moment or at a particular day [9].

In Iran OCP is the most common method of pregnancy prevention and the prevalence of OCP use is estimated to be $25 \%$ [10]. Yet, ministry of health believes this should be increased or at least to be maintained at the current level [11]. Thus, at policy levels to recognize any barrier in using OCP is considered curtail. Ministry 
of health reports that almost $35 \%$ of users usually discontinue the pill after 12 months of start [12]. Perhaps similar to other societies Iranian women also discontinue using OCP due to side effects. The purpose of this study was to determine the prevalence of mood changes in pill users and identify factors that predict mood changes. It was hoped that the study might contribute to the existing literature and provide a framework for the future interventions.

\section{Methods}

\section{Design and data collection}

This was a cross-sectional study. The study was carried out in Ahwaz, Iran during July 2011 to June 2012. A random sample of women aged 15-49 years old attending family planning centers in urban and rural locations were entered into the study. These centers offer free of charge services to women in reproductive ages. Women could register in a nearby center and usually attend these centers monthly. The centers offer OCP for those who wish and at the first inquiry health care workers provide both printed materials and verbal explanations for women. The centers also provide different services including counseling, family planning, and prenatal and postnatal care. The required sample size was calculated on the basis of findings from the Iran Integrate Monitoring Evaluation Survey (IMES) [10]. Women were recruited randomly from the registry list. To be included in the study, respondents had to be 15-49 years old, married and sexually active, using at least one-month LD pills, and being healthily (not having history of mood/ anxiety disorders, PMS/PMDD, and use of psychotropic medications). To collect data face-to-face interviews were conducted using a structured questionnaire. A team of trained public health students not connected to the family health services carried out all interviews.

\section{The questionnaire}

A three-part questionnaire especially designed for the study was developed. It contained items on demographic, side effects of pill use, and self-efficacy. These are presented as follows:

1. Demographic information: included recording of age, education, employment, ethnicity, place of living, and duration of OCP use of current formulation.

2. Side effects of oral pill use: First it was asked whether a respondent experienced any side effects due to the current OCP use. Then, if the answer was yes, we asked women to name any side effects they had experienced during $\mathrm{OCP}$ use. Respondents were allowed to name as many side effects as they experienced. Also we asked women whether they have received any information on OCP side effects from health care workers in the centers.
3. Self-efficacy: for the assessment of perceived selfefficacy, a six-item condition specific to oral pill selfefficacy scale was used. Items were generated from existing self-efficacy measures [13-15] as follows:

1. If I forget to use my pill, I can follow the instruction.

2. If I receive information on pill use, I can use it correctly

3. If I get sick when using oral pill, I can overcome the problem

4. If I get headache when using oral pill, I can overcome the problem

5. If I experience mood changes when using oral pill, I can overcome the problem

6. If I experience side effects, I can overcome the problem

Response categories ranged from 1 (not at all true) to 4 (exactly true) giving a total score ranging from 6 to 24 where the higher scores indicated higher self-efficacy. Reliability and stability of the item set as assessed by internal consistency and intra-class correlation coefficient (ICC) showed satisfactory results (Cronbach's alpha coefficient $=0.78$ and $\mathrm{ICC}=0.84$ ).

\section{Analysis}

Descriptive statistics was used to explore the data. Both univariate and multiple logistic regression analyses were used to assess the association between mood changes and independent variables including age, education, ethnicity, place of living, duration of OCP use, receiving information on OCP side effects, and self-efficacy. Data were analyzed using SPSS, version 16. Statistic significance was set at $\mathrm{P}<0.05$.

\section{Ethics}

The ethics committee of Tarbiat Modares University approved the study. All participants gave informed oral consent.

\section{Results}

In all 650 women were approached during the study period. Of these 50 women refused and the remaining 600 women agreed to take part in the study. However, due to several reasons including incomplete questionnaires, not using oral contraceptive pills, or not reporting side effects additional 100 women were excluded from the study; giving 500 questionnaires ready for the analysis. The mean age of participants was $27.5 \pm 5.6$ years, ranging from 15 to 47 years. Most women had primary education (58.2\%), and were housewife $(85 \%)$. The mean self-efficacy score was $12.9(\mathrm{SD}=2.70)$ raging from 6 to 24 and overall 94 women (18.8\%) indicated that they did not experience any side effects due to OCP use, while the remaining 406 women 
(81.2\%) reported that they were experiencing side-effects. The characteristics of respondents are shown in Table 1.

The most important side effects are presented in Table 2. As shown, 37.7\% reported mood changes during pill use. In order to assess the relationship between mood changes and independent variables we performed both univariate and multiple logistic regression analyses. For the analysis negative mood changes treated as dependent variable and demographic information, receiving information on OCP side effects from health care workers, and self-efficacy scores were considered as dependent variables. The results obtained from multiple logistic regression analysis indicated that women who reporting living in an urban setting $(O R=2.57,95 \%$ $C I=1.06-6.20, p=0.03)$, who did not receive information on OCP side effects $(O R=1.80,95 \% C I=1.15-2.80$, $p=0.009)$ and who reported lower self-efficacy scores $(O R=0.87,95 \% C I=0.80-0.94, p=0.001)$ were more likely to report experience of mood changes. The relationship between mood changes and others variables studied did not show any significant results. The results are shown in Table 3.

\section{Discussion}

The findings from this study indicated that the prevalence of reported mood changes due to OCP use among Iranian women appeared to be consistent with other studies. In addition the findings showed that receiving information on OCP side effects from health care workers and self-efficacy were important predicting factors for mood changes. The present study confirmed that most women who used oral pill faced several side effects. Women also reported that mood change was the most important side effects they have experienced during pill use. Unfortunately most warning notes on the pill packages do not address or acknowledge about

Table 1 The characteristics of the study sample

\begin{tabular}{|c|c|c|c|c|}
\hline & All $(n=500)$ & $\begin{array}{l}\text { Women experiencing OCP } \\
\text { side effects }(n=406)\end{array}$ & $\begin{array}{l}\text { Women not experiencing OCP } \\
\text { side effects }(n=94)\end{array}$ & P-value* \\
\hline \multicolumn{5}{|l|}{ Age (year) } \\
\hline Mean (SD) & $27.5(5.6)$ & $27.81(5.58)$ & $27.56(5.42)$ & 0.09 \\
\hline Range & $15-47$ & $15-43$ & $16-47$ & \\
\hline \multicolumn{5}{|l|}{ Parity (number) } \\
\hline Mean (SD) & $2.00(1.18)$ & $2.07(1.17)$ & $1.84(0.96)$ & 0.57 \\
\hline Range & $0-10$ & $0-7$ & $0-10$ & \\
\hline \multicolumn{5}{|l|}{ Duration of OCP use (months) } \\
\hline Mean (SD) & $25.1(3.45)$ & $27.75(6.79)$ & $23.44(10.03)$ & 0.34 \\
\hline Range & $5-55$ & $5-50$ & $5-55$ & \\
\hline Education (number, \%) & & & & 0.57 \\
\hline Illiterate/primary & $164(32.8)$ & $129(31.8)$ & $35(37.2)$ & \\
\hline Secondary & $291(58.2)$ & $240(59.1)$ & $51(54.2)$ & \\
\hline Higher & $45(9)$ & $37(9.1)$ & $8(8.6)$ & \\
\hline Ethnicity (number, \%) & & & & 0.84 \\
\hline Arab & $334(66.8)$ & $272(66.9)$ & $62(66.0)$ & \\
\hline Lor & $130(26)$ & $106(26.1)$ & $24(25.5)$ & \\
\hline Fars & $36(7.2)$ & $28(7.0)$ & $8(8.5)$ & \\
\hline Place of living (number, \%) & & & & 0.002 \\
\hline Rural & $75(15)$ & $51(22.6)$ & $24(25.6)$ & \\
\hline Urban & $425(85)$ & $355(77.4)$ & $70(74.4)$ & \\
\hline \multicolumn{5}{|l|}{ Self-efficacy score } \\
\hline Mean (SD) & $12.91(2.70)$ & $12.74(2.37)$ & $14.03(3.02)$ & 0.017 \\
\hline Range & $6-24$ & $6-24$ & $6-24$ & \\
\hline Receiving information on OCP side effects (number, \%) & & & & 0.001 \\
\hline Yes & $293(58.6)$ & $221(54.4)$ & $72(76.5)$ & \\
\hline No & $207(41.4)$ & $185(45.6)$ & $22(23.5)$ & \\
\hline
\end{tabular}

* Comparisons were made between women who did and did not report experiencing OCP use side effects. P-values derived from t-test for continuous data and chi-square for categorical information. 
Table 2 Side effects of the oral pill use reported by women $(n=406)$

\begin{tabular}{lll}
\hline The most important side effects & Number & $\%$ \\
\hline Mood changes & 153 & 37.7 \\
Nausea & 65 & 16.0 \\
Headache & 64 & 15.8 \\
Chloasma (facial pigmentation) & 44 & 10.9 \\
Decrease in sexual desire & 17 & 4.2 \\
Decreased bleeding & 14 & 3.4 \\
Other & 49 & 12.0 \\
\hline
\end{tabular}

mood changes adequately while this is an important issue for ensuring that women will continue to use pills in order to prevent at least unwanted pregnancies $[16,17]$. In fact, discontinuity of oral contraceptive pills might jeopardize women's health in general and reproductive health in particular $[18,19]$. A study from the USA found that $33 \%$ of oral contraceptive pills users discontinued using pills 6 months after the start due its side effects and $33 \%$ of these side effects were emotional and behavioral [4]. Similarly a study from UK showed that the incidence of depression and mood changes among the pill users was about 30\% [20]. Evidence from Iran suggest that barriers to use of OCP include health concerns, fear of side effects, misinformation, lack of confidence and sexual dissatisfaction $[21,22]$.
At least four explanations for OCP-related mood changes can be identified. A number of studies have explained some biochemical mechanisms for the effects of oral contraceptive pills on women's mood changes. In fact they believed that the components of pills such as estrogen and progesterone might cause these behavioral changes [23-25]. A number of investigators believed that rumors and speech about side effects of the pills that generally is said by friends, neighbors and the warning notes on the pill packages would lead to this condition [26-28]. However, some researchers demonstrated that although oral contraceptive pills could cause mood changes, they believed that it will stabilize after while $[9,29,30]$. Finally, a group of investigators argue that oral contraceptive pills have no effects on mood change at all [31,32].

Regardless of whatever the cause may be, the findings from the present study showed that there were significant association between mood changes and education on how to control side effects of pill, self-efficacy and place of living. Women who received education on how to control side effects of pill in family planning centers were more likely to report less mood changes compared to those who did not. In addition, women living in rural areas have reported lower mood changes in comparison with those who lived in urban environments. Perhaps since primary health care is more active in rural areas, women living in rural area receive more advice on oral pill use than women living in cities and metropolitans.

Table 3 The results obtained from logistic regression for reporting mood changes

\begin{tabular}{|c|c|c|c|c|}
\hline & $\mathrm{OR}^{*}(95 \% \mathrm{Cl})$ & $\mathbf{P}$ & $\mathrm{OR}^{* *}(95 \% \mathrm{Cl})$ & $\mathbf{P}$ \\
\hline Age & $0.99(0.956-1.028)$ & 0.650 & $1.00(0.96-1.04)$ & 0.894 \\
\hline Self-efficacy & $0.86(0.804-0.934)$ & 0.001 & $0.87(0.80-0.94)$ & 0.001 \\
\hline Duration of OCP use & $0.99(0.989-1002)$ & 0.179 & $0.99(0.98-1.00)$ & 0.357 \\
\hline \multicolumn{5}{|l|}{ Education } \\
\hline Illiterate/primary & 1.0 (ref.) & & 1.0 (ref.) & \\
\hline Secondary & $1.18(0.754-1.846)$ & 0.469 & $1.11(0.681-1.81)$ & 0.673 \\
\hline Higher & $1.83(0.837-3.873)$ & 0.110 & $2.06(0.881-4.81)$ & 0.096 \\
\hline \multicolumn{5}{|c|}{ Received information on OCP side-effects } \\
\hline Yes & 1.0 (ref.) & & 1.0 (ref.) & \\
\hline No & $2.08(1.387-3.135)$ & 0.001 & $1.80(1.15-2.80)$ & 0.009 \\
\hline \multicolumn{5}{|l|}{ Ethnicity } \\
\hline Arab & 1.0 (ref.) & & 1.0 (ref.) & \\
\hline Lor & $1.20(0.758-1.909)$ & 0.433 & $0.96(0.59-1.58)$ & 0.896 \\
\hline Fars & $2.11(0.967-4.630)$ & 0.061 & $1.76(0.75-4.12)$ & 0.189 \\
\hline \multicolumn{5}{|l|}{ Place of living } \\
\hline Rural & 1.0 (ref.) & & 1.0 (ref.) & \\
\hline Urban & $4.98(1.924-10.021)$ & 0.001 & $2.57(1.06-6.20)$ & 0.035 \\
\hline
\end{tabular}

* Derived from univariate multiple logistic regression analysis.

** Derived from multiple logistic regression analysis. 
Also women who had higher self-efficacy for using pill experienced less mood changes. Indeed women who had higher self-efficacy had more ability for controlling behavioral changes. Studies have suggested that identification of women who have low self-efficacy should be a priority and providers should promote self care ability and self-efficacy related to using OCP $[15,33,34]$. It is argued that people with low self-efficacy use avoidance coping strategies while people with high self efficacy use problem-focused coping strategies $[35,36]$.

The descriptive nature of this study might be considered as a limitation and the results should be interpreted with caution, although overall the findings from such studies might help to contribute to the topic. In addition, we relied on self-reported information while it seems that measuring mood changes need a valid and reliable instrument. Thus the findings should be interpreted with caution. Finally one should note that due to time constrain we chose a period of one month of OCP use as an inclusion criteria for this study and this may have been a limitation to our study results.

\section{Competing interests}

The authors declare that they have no competing interests.

\section{Authors' contributions}

GHS was the main investigator, collected the data, carried out the analysis and wrote the article. AH supervised the study and contributed to writing process. MEM and KK were the study advisors. SN contributed to the study design. AM contributed to the analysis, reviewed the first draft and provided the final manuscript. All authors read and approved the manuscript.

\section{Acknowledgements}

This article is part of the first author's PhD thesis at Faculty of Medical Sciences, Tarbiat Modares University. The authors gratefully acknowledge the clients, family planning managers of Ministry of Health, and health education experts from Khuzestan province for their cooperation and participation in the study.

\section{Author details}

${ }^{1}$ Department of Health Education, Faculty of Medical Sciences, Tarbiat Modares University, Tehran, Iran. ${ }^{2}$ Department of Public Health, Faculty of Medicine, Jundi Shapur University of Medical Sciences, Ahwas, Iran. ${ }^{3}$ Department of Public Health, Faculty of Health, Jundi Shapur University of Medical Sciences, Ahwas, Iran. ${ }^{4}$ Mental Health Research Group, Health Metrics Research Centre, Iranian Institute for Health sciences Research, ACECR, Tehran, Iran.

Received: 15 May 2013 Accepted: 6 September 2013 Published: 9 September 2013

\section{References}

1. Zlidar VM, Gardner R, Rutstein SO, Morris L, Goldber H, Johnson K: New Survey Findings: The Reproductive Revolution Continues. Population Reports, Series M, No. 17. Baltimore, MD: Johns Hopkins Bloomberg School of Public Health, Population Information Program; 2003.

2. Petitti D: Combination estrogen-progestin oral contraceptives. N Engl J Med 2003, 349:1443-1450.

3. Cleland J, Conde-Agudelo A, Peterson H, Ross J, Tsui A: Contraception and health. Lancet 2012, 380:149-156.

4. Sanders SA, Graham CA, Bass JL, Bancroft J: A prospective study of the effects of oral contraceptives on sexuality and well-being and their relationship to discontinuation. Contraception Journal 2001, 64:51-58.

5. Foster DG, Bley J, Mikanda J: Contraceptive use and risk of unintended pregnancy in California. Contraception 2004, 70:31-39.
6. Kurshan N, Neill EC: Oral contraceptives and mood in women with and without premenstrual dysphoria: a theoretical model. Archives of Womens Mental Health 2006, 9:1-14.

7. Mary A, Marcia L, Susan O, Wanzhu T, Dennis F: The influence of hormonal contraception on mood and sexual interest among adolescents. Arch Sex Behav 2008, 37:605-613.

8. Oinonen KA, Mazmanian D: To what extent do oral contraceptives influence mood and affect. J Affect Disord 2002, 70:229-240.

9. Jarva J, Oinonen KA: Do oral contraceptives act as mood stabilizers? Evidence of positive affect stabilization. Archives of Womens Mental Health 2007, 10:225-234.

10. Family and Population Health Deportment: Iran Integrate Monitoring Evaluation Survey (IMES). Tehran, Iran: Ministry of Health and Medical Education; 2005.

11. Rashidian A: Health Observatory:First Report I.R. Iran Multiple-Indicator Demographic and Health Survey. Theran: Ministry of Health and Medical Education, Population Report 2012, 3:154-165.

12. Nakhaee N: Assessing Family Planning Services Quality in Iran. Tehran, Iran: Ministry of Health and Medical Education; 2009.

13. Guide for Constructing Self-Efficacy Scales. http://www.uky.edu/ eushe2/ Bandura/BanduraGuide2006.pdf.

14. Scholz U, Sud SH, Dona B, Schwarzer R: Is general self-efficacy a universal construct? Eur J Psychol Assess 2011, 18:242-255.

15. Peyman N, Hidarnia A, Ghofranipour F, Kazemnezhad A, Oakley O, Khodaee G, Aminshokravi F: Self-efficacy : does it predict the effectiveness of contraceptive use in Iranian women ? Eastern Mediterranean health journal 2009, 15:1254-1262.

16. World Health Organization Department of Reproductive Health and Research (WHO/RHR) and Johns Hopkins Bloomberg School of Public Health/Center for Communication Programs (CCP): Family Planning: A Global Handbook for Providers (2011 update). Baltimore and Geneva: CCP and WHO; 2011.

17. Landry D, Wei J, Frost J: Public and private providers involvement in improving their patients' contraceptive use. Contraception 2008, 78:42-58.

18. Garbers S, Meserve A, Kottke M, Hatcher R, Chiasson MA: Tailored health messaging improves contraceptive and adherence: results from a randomized controlled trial. Contraception 2012, 86:536-542.

19. White KO, Westhoff C: The effect of pack supply on oral contraceptive pill continution: a randomized controlled trial. Obstetrics \& Gynecology 2011, 118:615-622.

20. O'Carroll R, Whittaker J, Hamilton B, Johnston M, Sudlow C, Dennis M: Predictors of adherence to secondary preventive medication in stroke patients. Ann Behav Med 2011, 41:383-390.

21. Rahnama P, Hidarnia A, Amin Shokravi F, Kazemnejad A, Ghazanfari Z, Montazeri A: Withdrawal users' experiences of and attitudes to contraceptive methods: a study from Eastern district of Tehran, Iran. BMC Publ Health 2010, 10:779.

22. Rahnama P, Hidarnia A, Amin Shokravi F, Kazemnejad A, Oakely D, Montazeri A: Why Iranian married women use withdrawal instead of oral contraceptives? A qualitative study from Iran. BMC Publ Health 2010, 10:289.

23. Carlstrom K, Karlsson R, Von Schoultz B: Diurnal rhythm and effects of oral contraceptives on serum dehydroepiandroster one sulfate (DHEAS) are related to alterations in serum albumin rather than to changes in adrenocortical steroid secretion. Scand Journal Clinical and Laboratory Investigation 2002, 62:361-368.

24. Epperson C, Wisner K, Yamamoto B: Gonadal steroids in the treatment of mood disorders. Psychosom Med 1999, 61:676-697.

25. Vallee M, Rivera JD, Koob G, Purdy RH, Fitzgerald R: Quantification of neurosteroids in rat plasma and brain following swim stress and allopregnanolone administration using negative chemical ionization gas chromatography mass spectrometry. Anal Biochem 2000, 287:153-166.

26. Ott MA, Shew ML, Ofner S, Tu W, Fortenberry JD: The influence of hormonal contraception on mood and sexual interest among adolescents. Archives of Sex Behavior 2008, 37:605-613.

27. West S, Stony CM, Hughes GW, Matacin M: Oral contraceptive use is associated with increased cardiovascular reactivity in nonsmokers. Annals Behavioral Medicine 2001, 23:149-157.

28. Robinson SA, Dowell M, Pedulla D: Do the emotional side effects of hormonal contraceptives come from pharmacologic or psychological mechanisms. Medicine Hypotheses 2004, 63:268-273. 
29. Abraham S, Luscombe G, Soo I: Oral contraception and cyclic changes in premenstrual and menstrual experience. Psychoses Obstetric Gynecologic Journal 2003, 24:185-193.

30. Rasgon N, Bauer M, Glenn T, Elman S: Menstrual cycle related mood changes in women with bipolar disorder. Bipolar Discord 2003, 5:48-52.

31. Bastani F, Mohammadi -yeganeh L: Does oral conteraceptive pill influence womens mood and stress level? Iran Obstetic and Gynecol Journal 2009, 60:65-74.

32. Ferrari M: Migraine as a process - challenges in the effective management of migraine. Funct Neural 2008, 23:153-160.

33. Hidarnia A: Comparing of Women's Knowledge and Attitudes towards Old and New Family Planning Services. Tehran, Iran: Ministry of Health and Medical Education; 2010

34. Eslami M: Assessment of the Effect of Integration of HBM and Self-Efficacy to Increase Quality of Family Planning Services. Tarbiat Modares University: PhD Thesis. School of Medical Sciences; 2010.

35. Povey R, Conner M, Sparks P: Application of the theory of planned behavior to two dietary behaviors: roles of perceived control and selfefficacy. Br J Health Psychol 2000, 5:121-137.

36. Tolma E, Belinda M, Alexandra E, John U: Examining the theory of planned behavior and theconstruct of self-efficacy to predict mammographyintention. Health Educ Res 2006, 33:233-251.

doi:10.1186/1742-4755-10-45

Cite this article as: Shakerinejad et al:: Factors predicting mood changes in oral contraceptive pill users. Reproductive Health 2013 10:45.

\section{Submit your next manuscript to BioMed Central and take full advantage of:}

- Convenient online submission

- Thorough peer review

- No space constraints or color figure charges

- Immediate publication on acceptance

- Inclusion in PubMed, CAS, Scopus and Google Scholar

- Research which is freely available for redistribution 